Peyman Mohammady, AlirezaBolhari, Mohsen Rajabi / TJMCS Vol .1 No.4 (2010) 402-412

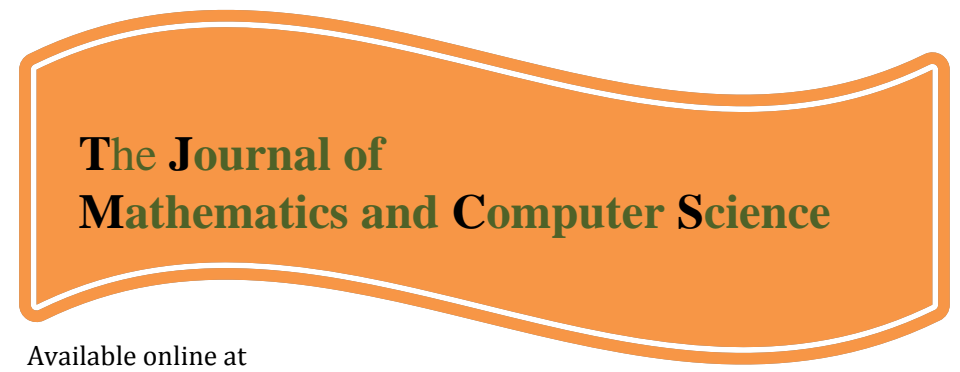

http://www.TJMCS.com

The Journal of Mathematics and Computer Science Vol .1 No.4 (2010) 402-412

\title{
The Application of Fuzzy Analysis on Modeling Behavioral Constructs; Appraisal of Informal Learning and Psychological Empowerment among Employees \\ Peyman Mohammady ${ }^{1,}$, Alireza Bolhari ${ }^{2}$, Mohsen Rajabi ${ }^{3}$ \\ Shahid Beheshti University, Pa.mohammady@yahoo.com \\ Shahid Beheshti University, Alireza@bolhari.com \\ Tehran University, mrajabi03@yahoo.com
}

Received: July 2010, Revised: October 2010

Online Publication: December 2010

\begin{abstract}
In the current ever-changing business world, organizations need to emphasize on employees as key element of acquiring competitive advantage. As managerial strategy, psychological empowerment has been less in consideration. In this context, authors investigated effects of informal learning on psychological empowerment. Both mentioned variables have been formed in individual context and led to organizational results in collective context. The contribution of this paper is the application of fuzzy logic on construct of appraisement model in better explaining of employee's behavior. It considers two important aspects of dynamic environment of organizations; first, uncertain environment of organizations and second, complexity of human behaviors which are ill-defined. The proposed model can be led to a better strategic planning of organization's social capital and can be applied to other contexts and would guide organizations to realistic appraisement of environmental factors. Authors have applied the proposed fuzzy-model in "Agricultural Jahad" organization and results are discussed.
\end{abstract}

Keywords: fuzzy expert system, fuzzy hypothesis analysis, individual development, informal learning, psychological empowerment

\footnotetext{
${ }^{1 *}$ Corresponding author: Master's Student, Information Technology Management, Faculty of Management and Accounting, Tehran, I.R. Iran.

${ }^{2}$ Master's Student, Information Technology Management, Faculty of Management and Accounting, Tehran, I.R. Iran.

${ }^{3}$ Master's Student, Industrial Management, Faculty of Management and Accounting, Tehran, I.R. Iran.
} 


\section{Introduction}

Learning is defined as a rather stable change in behavior or potential behavior which derives from direct or indirect experience[1]. If the definition is agreed upon, then some points have to be taken into consideration. First, learning involves change. Second, the change derived from learning is quite stable. The third point is the reason to say that learning has effects on potential behavior. Since it is impossible to read one's mind, it is necessary to rely on observing to identify the obtained cognition. A typewriter types eighty five words per minute after apprenticeship, whereas he used to type seventy words. It can be said that learning has occurred. An employee who gets to work on time is motivated when he watches the boss blaming another employee for being late. Although the real behavior of the employee has not been changed, he has learnt not to be late. It is mentioned that change occurs from direct or indirect experience. In the typewrite example he or she practiced and typed a lot in the apprenticeship and the learning is derived from direct experience. However, in the next example the employee just learnt through observing. Nothing has been told to him, so it is said that learning is obtained from indirect experience.

At first we commence explaining the differences and interactions between formal and informal learning. This can help clarify the indirect effects informal learning has on the organization through formal learning. In other words, any effects of informal learning on organizational learning (formal learning) are said to have positive influences on employees' empowerment. Following that, there are the explanation of empowerment, its concepts and the theoretical relationships between informal learning and psychological empowerment which are then tested.

\section{The differences between formal and informal learning}

Informal learning occurs in some employees' tacit activities and routines. It is clearly unstructured, experimental and it cannot be taught[2]. Informal learning can be an incident and integrated with daily activities [3]. Also it can be somehow intentional and potentially structured [4]. Informal learning sometimes defined as any types of learning occurs out of the class [3], [5],[6], and [7].This learning possibly happens either in intentional activities or unintentional ones that are not desirable for the learner.

The degree of control shows the person's degree of autonomy in identifying learning process. Physical location depicts the learning environment. And the last category mentions the goals to which learning process is designed to reach. The more the degree of unstructured process is, the higher the level of informality would be. If the locations and environment are similar to classes, learning is more like the formal type. Contrary to that, if the environment is more like office environment, friends' groups or natives' community, then the learning is more informal. Goals refer to the dimensions of training the organization expects. Content is defined as what is learnt.

As shown in figure 1 there is a kind of acceptance and accordance in informal learning which does not exist in formal learning. A research which has been conducted by Sally Ann Moorein 1998 depicts these stages and can clarify the differences between two types of learning [8].

\section{Factors affecting informal learning}

The factors of the structure of an organization which affect informal learning are discussed in this section. An organization can be observed in three levels: organizational, team and individual level [9]. While each level has its attributes and characteristics, all of them shares in the success of the organizational learning.In the organizational level, learning is considered as a group experience and an intention to get results from studying the organization's environmental effects. Learning in the team level is defined as a mutual structure of the new knowledge which is able to act cooperatively [9]. The individual level is a method by which people acquire knowledge and skills [9] through promoting inquiries and dialogues while creating learning opportunities [10]. The fundamental level of a learning 
organization is the individual level. Most of the researches on organizational learning have focused on organizational level rather its correlations to individual learning level[4], [11], [12], and [13].

It is necessary to mention that $\% 80$ of the work environmental learning occurs through informal implications whereas just \%20 of companies' investment is allocated to that [14]. As mentioned before, from individual level of learning, informal learning may be influenced by factors such as education field, gender or age.In a researchBergand Chyungstudied the impact of age and two other factor of gender and education field on the employees' involvement degree in informal learning activities [15]. Furthermore, a two-way analysis of variance implemented to ensure that the joint effect of two factors of education field and gender has been considered. This research showed that there is a meaningful relationship between age and the degree of involvement in learning. The result of this relationship analysis showed a positive correlation between these two factors. But, in the analysis no meaningful relationship has found between informal learning and these factors and even in case of the effect of these two factors on informal learning activities and the degree of involvement in it. This could be considered by firms that have low education level employees. In other word, although an organization may have low education personnel, it can be completely hopeful to informal learning and management should looks forward programs to reinforce this level of learning and seeking to be a learner organization. These findings were consistent with reference [16] that had studied these factors.

In the part of cognitive factors that can influence on informal learning, Berg and Chyung categorize many factors and analyze each ones` effect on this type of learning [15]. From 10 factors which were ranked by respondent in questionnaire, the amount of interest in the current job was identified as the most effective factor in the degree of involvement in informal learning. It is a logical finding that people tend to spend their time on things they are interested in. The least effective factor in informal learning was monetary prizes. It may because involvement in informal learning is an independent and selfdirected activity and is more influenced by internal motivators (such as jobs field) rather than external ones (such as monetary prizes).

In the part of organizational and structural factors; no meaningful relationship was found between learning culture and informal learning in reference [15]. This may somehow be surprising, but to explain why there was not found any meaningful correlation between informal learning and the culture of learner organization, it can be said that in fact individual learning is just one of the many components of learner organization culture.

\section{Informal and Formal Learning Relations}

Although informal and formal learning have differences, they possibly have influences on each other in an organization. As stated before, other structural factors among gender factors may affect this relationship.As the relationship between formal and informal learning is important, it is being discussed in a separate title.In some occasions where formal learning takes place in an informal environment, such as searching through internet and participating in electronic courses, their effectiveness is increased [17].Figure 1 illustrates how competence involves a set of theoretical and practical knowledge. Usually a formal education improves the ability to assimilate informal learning at the workplace. The main reason is that experiential learning assumes explicit knowledge andconceptual tools about the task and the work process that can be used by the learning subject to discover and interpret experiences. Simultaneously, it has been shown to be very difficult to develop explicit knowledge through experience [18]. 


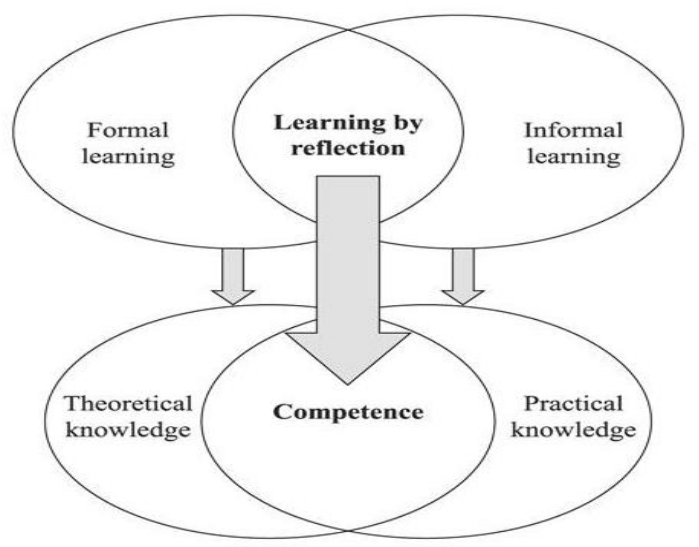

Figure 1, Learning by reflection brings about competence

Results from a research showed formal learning behaviors would have a positive but reducing effect on informal learning behaviors and informal learning behaviors would have a positive but reducing effect on formal behaviors. Also it reveals a constantly positive effect of informal learning behaviors on formal behaviors as shown in figure 2 [19].
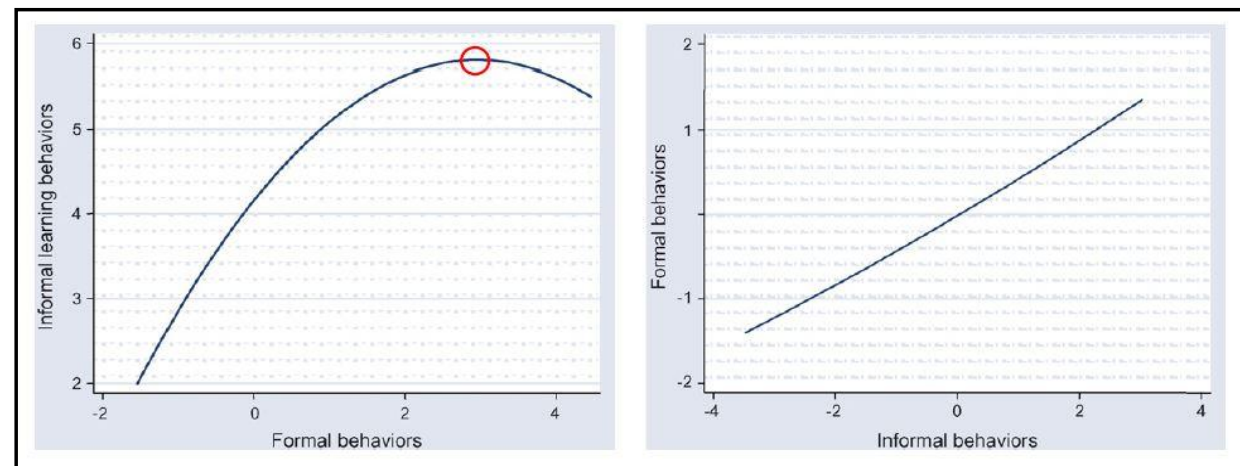

Figure. 2,The effect of formal behavior on informal learning behaviors, and informal behaviors on formal learning behaviors [19]

As it is shown in figure 2, informal learning can be developed through formal learning to an identified degree (red circle). Informal learning will be diminished after this point. This finding, which approves Ellstrom and Svensson research results [20], will help human resource managers in conducting formal learning behaviors in organizations.

\section{Informal Learning and Employee Empowerment}

There is still a debate concerning the meaning of the empowerment [21].However Holt et al.define empowerment as "a perception that an employee holds" [22]. The concept of empowerment engages the workforce being provided with a deeper degree of flexibility and more freedom to make decisions [23].As stated earlier in this paper, about $80 \%$ of the learning of employees is through informal activities.Previous researches have shown a positive relationship between training and human resource empowerment.So, informal learning seems to be an important factor in empowering employees along with formal learning [21].

In this paper, the effects of informal learning of psychological empowerment of employees are investigated.Researchers have investigated empowerment in two major fields: First, aiming at the conditions available in an organization for empowerment and second by focusing on employees [24].Reference [25] is a proof to the statement that power has a key role in defining 
empowerment.Reference [26] defines empowerment with emphasis on to authorize and to give power to someone. Reference [27] has investigated empowerment in three fields: action (delegation), process (the way employee feels power) and psychology (psychological outcomes).As stated before, empowerment is discussed from aspects. The first one looks at organizational policies and structure which brings more authority to work. This is called the "structural empowerment" [28],[29],and [30].This type of empowerment is related to power allocation in organization. Reference [31] names this social-structural empowerment. Reference [32] also called this the "behavior aspect of supervisors". The second aspect focuses on employees' perception. This is called the psychological empowerment [22], [33], and[34].

This research was conducted in a service-based company. In product-based companies outcomes are tangible, while in service-based ones it is difficult to measure the level of empowerment. In such situations, other factors may be useful, for instance customer satisfaction, job satisfaction, employee evaluation, etc.Although in Meyerson and Kline's researches no relation between organizational commitment and job satisfaction with psychological empowerment was found, they showed that psychological empowerment can positively predict employee performance [24]. So as the purpose of this paper is to investigate informal learning and psychological empowerment, its questionnaire was bounded to employees' perceptions and thoughts [24].In spite of social-structural empowerment, psychological empowerment can be measured only by Spreitzer's questionnaire [31].This questionnaire consists of four major parts measuring competence, meaning, self-determination and impact.For informal learning Berg and Chyung's questionnaire were used [15].

\section{Research Method and Hypotheses}

The distributed questionnaire consisted of three sections; demographic questions, informal learning questions and psychological empowerment questions. Due to the fuzzy nature of the research, hypotheses of the study do not follow the conventional statistical analyses (null hypothesis test). These fuzzy-based analyses try to calculate attainable probability of each of the rules in the knowledge base in order to be fired. The term "degree of support" (DOS) is discussed in such situations. DOS provides the weight of each rule which is fired. So the probability of firing different rules is considered in data analysis.

- Analysis 1: What is the most probable psychological empowerment level based on different age levels?

- Analysis 2: What is the most probable psychological empowerment level based on employment?

- Analysis 3: What is the most probable psychological empowerment level based on informal learning?

The questionnaires were distributed among "Agricultural Jahad's Organization of Qazvin's Province" including offices, cities' management, groups, services' centers and other dependent organizations. Among 125 questionnaires, 97 were collected and were valid (return rate: 77.6\%). With regard to the low variance of informal learning (about 0.85) and psychological empowerment (about 0.67) in preliminary tests, the minimum number of samples (estimated error 0.25 at $95 \%$ confidence level) was 47 .

\section{Data Analysis}

Data were analyzed with SPSS version 16 and FuzzyTech version 5.72. The calculated Cronbach's alpha for informal learning and psychological empowerment were 0.778 and 0.875 respectively. The combined Cronbach's alpha for questionnaire was 0.83. According to Kolmogorov-Smirnov test, informal learning and psychological empowerment have a good fit to normal distribution. The modeling and simulation process of the current study is performed with neural-learning process with FuzzyTech software. The neural-learning process refers to identification of each rule's weight in knowledge base from real data to form and tune the neural-fuzzy expert system. 


\section{Results}

\subsection{Descriptive Statistics}

Table 1 shows the demographics of respondents. As it is shown in table 2 the respondents are 37 years old in average, the informal learning average score is about 4.1 (slightly higher than average), the empowerment of employees' average level is 5.45 (slightly higher than average) and the job satisfaction mean is about 4.6 (higher than the average). The low variance of informal learning and empowerment show good fit to normal distribution.

Table 1, Demographics of respondents

\begin{tabular}{llllll}
\hline $\begin{array}{l}\text { Variable } \\
\text { Gender }\end{array}$ & Number & Percent & $\begin{array}{l}\text { Variable } \\
\text { Age }\end{array}$ & Number & Percent \\
$\quad$ Male & 77 & 80.6 & 26 to 30 & 26 & 26.8 \\
$\quad$ Female & 20 & 19.4 & 31 to 35 & 10 & 10.5 \\
Organization Level & & & 36 to 40 & 26 & 26.8 \\
$\quad$ Expert Position & 58 & 59 & 41 to 45 & 22 & 22.6 \\
$\quad$ Management Position & 39 & 41 & 46 to 50 & 11 & 11.3 \\
Education & & & $>51$ & 2 & 2.0 \\
$\quad$ Undergraduate & 68 & 70.2 & & & \\
Graduate & 28 & 28.8 & & & \\
phD & 1 & 1 & & & \\
Total & 97 & 100 & & & \\
\hline
\end{tabular}

The descriptive statistics of informal learning is shown in table 3. According to this research the most common learning activity among employees is learning through getting feedback of their activity from the environment. However, the least common is learning through electronic dialogues like chatting rooms and emails. This issue would be significant while trying to integrate formal and informal learning; that is applying formal learning through informal learning methods that have been explained before.

Table 2, Descriptive Statistics

\begin{tabular}{|l|c|c|c|c|c|}
\hline & $\mathrm{N}$ & Minimum & Maximum & Mean & Std. Deviation \\
\hline Age & 97 & 26 & 55 & 37.23 & 6.992 \\
\hline dur_Emp & 97 & 6 & 341 & 158.06 & 89.586 \\
\hline Satisfaction & 97 & 1 & 7 & 4.96 & 1.406 \\
\hline Collaboration & 97 & 1 & 7 & 5.52 & 1.332 \\
\hline Knowledge_transferriing & 97 & 1 & 7 & 4.79 & 1.099 \\
\hline Informal-Learning-Average & $\mathbf{9 7}$ & $\mathbf{1 . 7 8}$ & $\mathbf{6 . 3 3}$ & $\mathbf{4 . 0 7 1 1}$ & $\mathbf{. 8 7 5 7 4}$ \\
\hline EM_average_Meaning & 97 & 1.00 & 7.00 & 5.5949 & 1.00631 \\
\hline EM_average_Competence & 97 & 2.00 & 7.00 & 5.9485 & .82993 \\
\hline EM_average_Self_Determination & 97 & 1.00 & 7.00 & 4.8174 & 1.12174 \\
\hline EM_average_Impact & 95 & 2.00 & 7.00 & 5.0036 & 1.15090 \\
\hline Empowerment-Average & $\mathbf{9 7}$ & $\mathbf{1 . 3 3 3}$ & $\mathbf{6 . 6 6 7}$ & $\mathbf{5 . 4 5 3 6 2}$ & $\mathbf{. 7 6 9 7 9 4}$ \\
\hline
\end{tabular}

Table 3, Descriptive Statistics of Informal Learning

\begin{tabular}{|l|c|c|c|c|c|}
\hline & $\mathrm{N}$ & Minimum & Maximum & Mean & Std. Deviation \\
\hline IL*_Reflect & 97 & 1 & 7 & 4.95 & 1.228 \\
\hline IL_tray_and_error & 97 & 2 & 7 & 4.61 & 1.418 \\
\hline IL_observing & 96 & 2 & 7 & 3.62 & 1.438 \\
\hline IL_search_onthe_web & 97 & 1 & 7 & 4.06 & 1.701 \\
\hline IL_Journal & 97 & 1 & 7 & 3.62 & 1.661 \\
\hline IL_Conversation & 97 & 1 & 7 & 4.93 & 1.394 \\
\hline IL_chat & 97 & 1 & 7 & 2.42 & 1.457 \\
\hline IL_multimedia_training & 97 & 1 & 7 & 3.81 & 1.467 \\
\hline
\end{tabular}




\begin{tabular}{|l|c|c|c|c|c|}
\hline IL_books & 97 & 1 & 7 & 4.61 & 1.462 \\
\hline IL_average & $\mathbf{9 7}$ & $\mathbf{1 . 7 8}$ & $\mathbf{6 . 3 3}$ & $\mathbf{4 . 0 7 1 1}$ & $\mathbf{. 8 7 5 7 4}$ \\
\hline
\end{tabular}

* IL: Informal Learning

Analyzing the psychological empowerment shows that the employees' perception of empowerment mostly equals eligibility and qualification, while being significant in their work processes is the last perception. That is, employees do not understand flexibility and delegation of authority in their field of work. Table 3 also shows that meaningfulness and employees' perceptions from the work accordance and its importance is quite high. Regarding the average amount of empowerment, which is 5.45, it can be inferred that the employees are in appropriate level according to the psychological empowerment.

Table 4, Descriptive Statistics of Psychological Empowerment

Table 4, Descriptive Statistics of Psychological Empowerment
\begin{tabular}{|l|c|c|c|c|c|}
\hline & $\mathrm{N}$ & Minimum & Maximum & Mean & Std. Deviation \\
\hline EM*aaverage_Meaning & 97 & 1.00 & 7.00 & 5.5949 & 1.00631 \\
\hline EM_average_Competence & 97 & 2.00 & 7.00 & 5.9485 & .82993 \\
\hline EM_average_Self_Determination & 97 & 1.00 & 7.00 & 4.8174 & 1.12174 \\
\hline EM_average_Impact & 95 & 2.00 & 7.00 & 5.0036 & 1.15090 \\
\hline EMpowerment_average & $\mathbf{9 7}$ & $\mathbf{1 . 3 3 3}$ & $\mathbf{6 . 6 6 7}$ & $\mathbf{5 . 4 5 3 6 2}$ & $\mathbf{. 7 6 9 7 9 4}$ \\
\hline
\end{tabular}

* EM: Empowerment

\subsection{Analysis}

Figure 3 and 4 depict the effects of age and informal learning on psychological empowerment. These plots have been illustrated after the learning process occurred and been affected by adjusted degree of support (DOS). According to figure 4 at same levels of age -youth- higher levels of empowerment's perception is observed while informal learning levels increase. At medium level of age, after specific level, increasing informal learning activities results in the decrease of the levels of empowerment perception among employees and also it has descending rate. At higher levels of age, neither relationships nor effects of above variables on perception of empowerment can be found. This is interpretable because of the main range of participants belong to young and medium levels; which is evident in results of descriptive statistics shown in table 1.

The most important managerial practices that should be concentrated on are age and measures of employees' informal learning. In other word focusing on lower levels of age results in persuading employees to accelerate informal learning activities from lower levels to medium levels. Organization should empower employees at medium level of age to limit accelerating informal learning from specific level of informal learning because the increase in this level leads to the decrease of empowerment's perception.

Among rules of DOS which have been calculated, some rules have higher firing degree or have more attainable probability. These rules can be confirmed as prominent and stabilized hypotheses. The main difference between statistical hypothesis analysis and fuzzy hypothesis analysis belongs to this area- Pvalue and DOS. Some of the rules are shown in table 4.
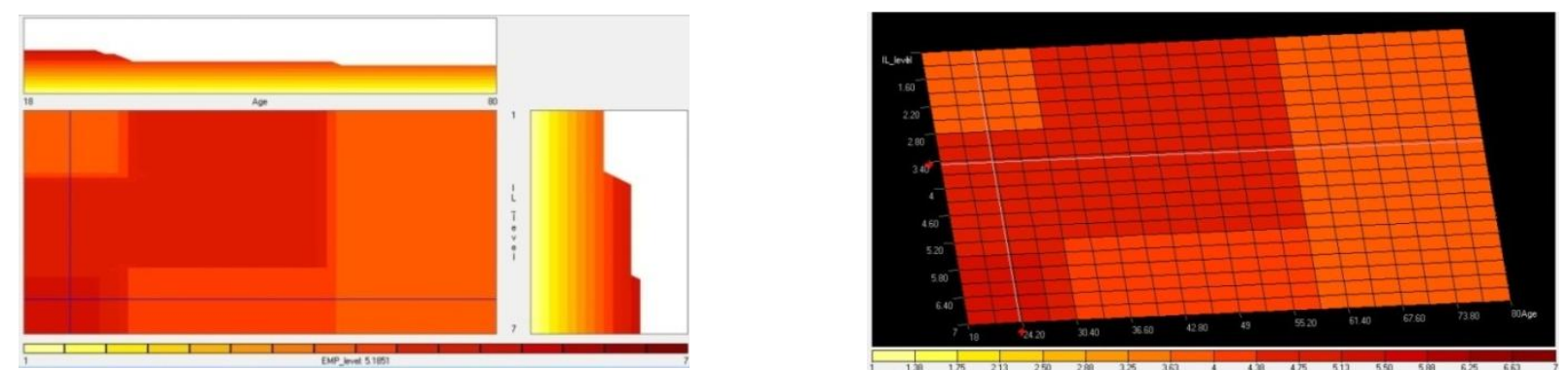

Figure3. The 2D plot for first analysis - The effect of age and informal learning on Psychological Empowerment 


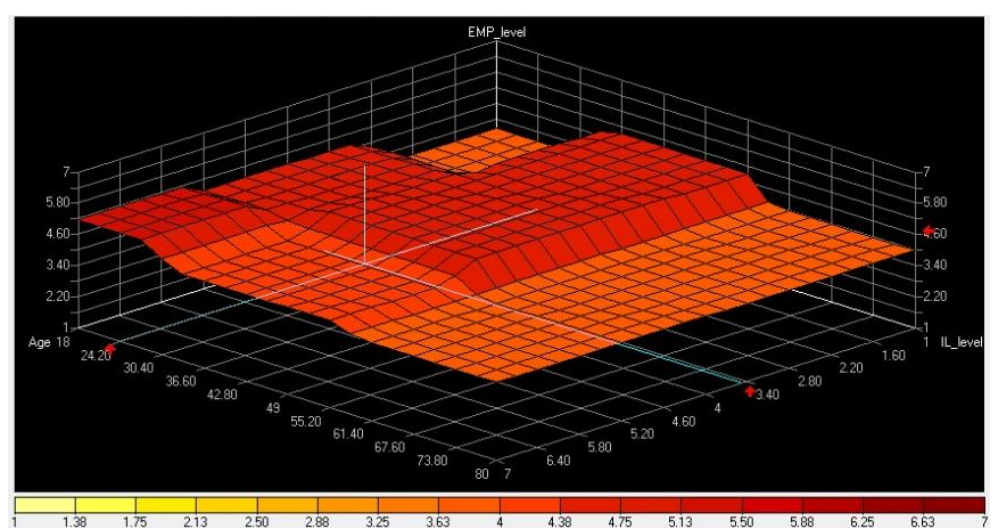

Figure4. The 3'D plot for first Analysis - The effect of age and informal learning on Psychological Empowerment

Table 5,The selection of some calculated rules of DOS - Decision Making

\begin{tabular}{|c|c|c|c|c|c|}
\hline \multicolumn{2}{|c|}{ IF } & \multicolumn{2}{c|}{ THEN } \\
\hline Rule no. & Age & Education_level & IL_level & DOS & EM_level \\
\hline 3 & Young & Graduated & Low & 0.40 & High \\
\hline 12 & Median & Graduated & Low & 1.00 & High \\
\hline 8 & Young & Graduated & High & 0.90 & Medium \\
\hline 17 & Median & Graduated & High & 1.00 & Medium \\
\hline
\end{tabular}

According to table 5, at lower levels of informal learning, higher levels of age lead to higher psychological environment psychological empowerment among employees. The calculated and simulated DOS to fire the rule number 12 is 2.5 times greater than rule number 3 . Instead at higher levels of informal learning higher levels of age lead to lower levels of psychological environment; firing's probability of rule number 17 is greater than rule number 8 . These results are compatible with above analysis that has been described in figure 2 and 3. It can be concluded that the organization should persuade the youth to enhance informal learning activities, and the other ones to different motivation ways, for example control level of informal learning activities among higher ages.

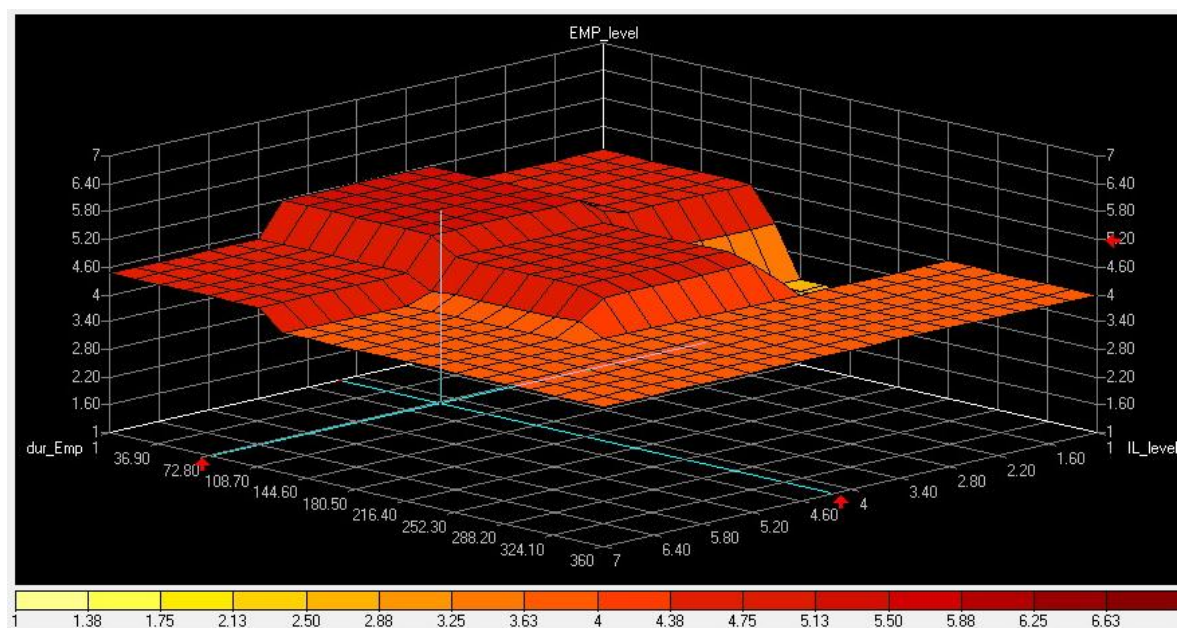

Figure5, The 3'D plot for second analysis - The effect of informal learning and employment's duration on Psy. Empowerment

Figure 5 shows effects of employment's duration and informal learning on psychological empowerment. At the second effect, as illustrated in the plot, with increasing of employment's duration to a specific level of informal learning activity, employees' perception of empowerment increases and then decreases. At the same level of informal learning activity, at higher level of employment's duration, 
psychological empowerment decreases. According to above lines, if the organization tends to concentrate on motivation and stimulation plans for informal learning dependent on employment's duration, it should try to enhance informal learning activities from low level to medium level. The reason is that the increase in informal learning in this area results in higher psychological empowerment. Also it should limit informal learning activity from increasing a lot in order to avoid higher descending trend of psychological empowerment. However, at the same age level, the results may lead to incoherent and complex situations. For comprehensive analysis, a complementary table status should be surveyed showing DOS rules. After that, other variables status that has presented good rules should be considered as core knowledge base.

Table 6 shows a cross-cutting of DOS rules. A comparison between rules number 32 and 5 shows that in the same levels of informal learning and employment's duration, higher ages result in lower psychological empowerment levels. Also comparison between rules number 14 and 41 or number 1 and 28 accord with this statement. Comparing rules number 5 and 14 or number 41 and 50 at the same levels of informal learning and age shows that higher levels of employment's duration lead to higher levels of psychological empowerment. The degree of support for such rules is greater than same rules with lower employment's duration.

Table 6, Selection of some calculated DOS rules - Decision Making

\begin{tabular}{|c|c|c|c|c|c|}
\hline & \multicolumn{3}{|c|}{ IF } & \multicolumn{2}{c|}{ THEN } \\
\hline Rule no. & Age & Duration_Emp & IL_level & DoS & EM_level \\
\hline 5 & Young & Low & Medium & 0.90 & Medium \\
\hline 32 & Median & Low & Medium & 0.70 & Medium \\
\hline 14 & Young & Medium & Medium & 1.00 & Medium \\
\hline 41 & Median & Medium & Medium & 0.70 & Medium \\
\hline 50 & Median & High & Medium & 0.90 & Medium \\
\hline 1 & Young & Low & Low & 0.30 & Low \\
\hline 28 & Median & Low & Low & 0.10 & Low \\
\hline
\end{tabular}

However, comparing rules number 5 and 1 or rules number 32 and 28, effects of informal learning on psychological environment is perfectly evident.

\section{Conclusion}

With regard to what has been explained in the previous sections, learning is defined as a stable change in behavior or potential behavior that derives from direct or indirect experience. The unstructured experimental type of learning is called informal learning. The one which can be taught systematically is said to be formal learning. Informal learning is ignored a lot; that is $\% 80$ of the work environmental learning occurs through informal implications whereas just $\% 20$ of companies' investment is allocated to that.

This paperis a case study conducted in a service-based company. In product-based companies outcomes are tangible, while in service-based ones it is difficult to measure the level of empowerment. In such situations, other factors may be useful, for instance customer satisfaction, job satisfaction, employee evaluation, etc. the questions were the most probable psychological empowerment level based on different age levels, the most probable psychological empowerment level based on employment, and the most probable psychological empowerment level based on informal learning. The questionnaires were distributed among offices, cities' management, groups, services' centers and other dependent organizations of Agricultural Jahad's Organization of Qazvin's Province. According to KolmogorovSmirnov test, informal learning and psychological empowerment have a good fit to normal distribution. The modeling and simulation process of the current study is performed with neural-learning process with FuzzyTech software.

According to this research the most common learning activity among employees is learning through getting feedback of their activity from the environment. However, the least common is learning through electronic dialogues like chatting rooms and emails. This issue would be significant while trying to integrate formal and informal learning; that is applying formal learning through informal learning 
methods that have been explained before.Analyzing the psychological empowerment shows that the employees' perception of empowerment mostly equals eligibility and qualification, while being significant in their work processes is the last perception. Regarding the average amount of empowerment, which is 5.45 , it can be inferred that the employees are in appropriate level according to the psychological empowerment.

In addition to that it has been proved that focusing on lower levels of age results in persuading employees to accelerate informal learning activities from lower levels to medium levels. The organization should empower employees at medium level of age to limit accelerating informal learning from specific level of informal learning because the increase in this level leads to the decrease of empowerment's perception.

It can be concluded that the organization should persuade the youth to enhance informal learning activities, and the other ones to different motivation ways, for example control level of informal learning activities among higher ages. Also if the organization tends to concentrate on motivation and stimulation plans for informal learning dependent on employment's duration, it should try to enhance informal learning activities from low level to medium level.

\section{References}

[1]Aiken, L.R., "Assessment of intellectual functioning", Allyn\& Bacon, 1987.

[2]Marsick, V.J.and Volpe, M., "The nature and need for informal learning", Advances inDeveloping Human Resources, Vol. 1, No. 1, pp. 1-9, 1999.

[3]Hadkinson, H., and Hadkinson, P., "Learning in differing communities of practices: a case study of UK secondary school teachers", Proceeding of Researching Work and Learning Conference, pp. 25-27, 2003.

[4] Thomas, K., and Allen, S., "The learning organization: a meta-analysis of themes in literature", The Learning Organization, Vol. 13, No. 3, pp. 123-39, 2006.

[5]Kremer, A.L.,"Predictors of Participation in Formal and Informal Workplace Learning: Demographic, Situational, Motivational, and Deterrent Factors", PhDDissertation, George Mason University, Fairfax, VA, 2005.

[6]Reardon, R.F., "Informal learning after organizational change", Journal of Workplace Learning, Vol. 16, No 7 and 8 , pp. 385-95, 2004.

[7]Slater, T.R., "Informal Learning in the Workplace: Identifying Contextual Factors Affecting Employee's Ability to Engage in Informal Learning in the Nonprofit Financial Services Industry", PhD Dissertation, Capella University, Minneapolis, MN, 2004.

[8]Moore, S.A., "Time-to-Learning", Digital Equipment Corporation, 1998.

[9]Marsick, V.J., and Watkins, K.E., New Directories for Adult and Continuing Evacuation, C)Jossey-Bass, A Publishing Unit of John Wiley \& Sons, Inc., Spring 2001.

[10]0'Neil, J.,"Participants' guide for interpreting the results of the Dimensions of the Learning Organization Questionnaire", Advances in Developing Human Resources, Vol. 5, No. 2, pp. 222-30, 2003.

[11]Garavan, T., "The learning organization: a review and evaluation", The Learning Organization, Vol. 4, No. 1, pp. 18-29, 1997.

[12]Lee, Y.J., and Roth, W.M.,"The individual collective dialectic in the learning organization", The Learning Organization, Vol. 14, No. 2, pp. 92-107, 2007.

[13]Small, A., and Irvine, P., "Towards a framework for organizational learning", The Learning Organization, Vol. 13 No. 3, pp. 276-99, 2006.

[14]Cross, J., "Informal Learning: Rediscovering the Natural Pathways that Inspire Innovationand Performance", Pfeiffer, San Francisco, CA, 2007.

[15] Berg, S.A., and Chyung, S.Y., "Factors that influence informal learning in the workplace", Workplace Learning, Vol. 20, No. 4, pp. 229-244, 2008.

[16] Livingstone, D.W., "Adults' Informal Learning: Definitions, Findings, Gaps and Future Research", NALL Working Paper, No. 21, OISE/UT, Toronto, Available https://tspace.library.utoronto.ca/bitstream/1807/2735/2/21adultsinformallearning.pdf (Accessed: 25 Sep. 2010) [17] Barnett, R., "Learning to work and working to learn", in Boud, D., and Garrick, J. (Eds), "Understanding Learning at Work", Routledge, London, 1999.

[18] Brehmer, B., "In one word: not from experience", ActaPsychologica, Vol. 45, pp. 223-41, 1980. 
[19]Janowicz-Panjaitan, M., Noorderhaven, N.G., "Formal and informal interorganizational learning within strategic alliances", Elsevier Research Policy, Vol. 37, pp. 1337-1355, 2008.

[20]Ellstrom, P., and Svensson, L., "Integrating formal and informal learning at work", The Journal of Workplace Learning, Vol. 16 No. 8, pp. 479-49, 2004.

[21] Kay Greasley, K., Bryman, A., Dainty, A., Price, A., Naismith, N., and Soetanto, R., "Understanding empowerment from an employee perspective: What does it mean and do they want it?" Team Performance Management, Vol. 14, No. 1/2, pp. 39-55, 2008.

[22] Holt, G.D., Love, P.E.D., and Nesan, L.J., "Employee empowerment in construction: an implementation model for process improvement", Team Performance Management, Vol. 6, No. 3/4, pp. 47-51, 2000.

[22]McHugh, M., O'Brien, G., and Ramondt, J., "Organizational metamorphosis led by front line staff", Employee Relations, Vol. 21, No. 6, pp. 556-76, 1999.

[23] Walton, R., "From control to commitment in the workplace", Harvard Business Review, March-April, pp. 77-84, 1985.

[24]Meyerson, S.L., Kline, T. J.B., "Psychological and environmental empowerment: antecedents and consequences", Leadership \& Organization Development Journal, Vol. 29, No. 5, pp. 444-460, 2008.

[25] Conger, J.A., and Kanungo, R.N., "The empowerment process: Integrating theory and practice", Academy of Management Review, Vol. 13, pp. 471-483, 1988.

[26] Tulloch, S. (Ed.), "The reader's digest oxford word finder", Clarendon, oxford, 1993.

[27]Menon, S.T., "Employee empowerment: an integrative psychological approach", Applied Psychology: an International Review, Vol. 50, No. 1, pp. 153-80, 2001.

[28]Liden, R.C., and Arad, "A power perspective of empowerment and work groups: Implication for HRM research", In G.R. Ferris (Ed.), Research in personnel and HRM, Vol. 14, pp. 205-252, 1996.

[29]Eylon, D., and Bamberger, P., "Empowerment cognitions and empowerment acts: recognizing the importance of gender", Group and Organization Management, Vol. 25, No. 4, pp. 354-72, 2000.

[30] Mills, P.K., and Ungson, G.R., "Reassessing the limits of structural empowerment: organizational constitution and trust as controls", Academy of Management Review, Vol. 28, No. 1, pp. 143-53, 2003.

[31]Spreitzer, Gretchen M.,"Psychological empowerment in the workplace: Dimensions, measurement, and validation",Academy of Management Journal, Vol. 38, No. 5, pp. 1442-1465, 1995.

[32]Lee, M., and Koh, J.,"Is empowerment really a new concept?",International Journal of Human Resource Management, Vol. 12, No. 4, pp. 684-95, 2001.

[33]Peccei, R., and Rosenthal, P., "Delivering customer-oriented behavior through empowerment: an empirical test of HRM assumptions", Journal of Management Studies, Vol. 38, pp. 831-857, 2001.

[34]Thomas, K. W., and Velthouse, B. A., "Cognitive elements of empowerment: an interpretive model of intrinsic task motivation", Academy of Management Review, Vol. 15, No.4, pp. 666-681, 1990. 